\title{
MOVIMENTO SOCIAL E PARTICIPAÇÃO: A SAÚDE NA ESFERA PÚBLICA
}

Rubens de C.F. Adorno

Esse artigo baseia-se no trabalho "A trajetória do movimento e da participação: a conduta dos atores sociais na saúde", tese de doutorado apresentada ao Departamento de Prática de Saúde Pública/FSP. Destaca o problema da diferença conceitual entre o tema dos "movimentos sociais" e da "participação", em termos de diferentes tradiçōes téricas. A partir de um cenário local - 0 Município de São José dos Campos - são referidos e interpretados os atores sociais que, a partir do tema ou da ação na área da saúde, se representam na esfera pública. Conclui a questão da existência de um "movimento social" no Brasil contemporâneo, que a partir de discursos e ações coletivas busca interferir nas orientaçōes culturais da sociedade, expressando-se através da saúde, em diferentes tipos de organizaçōes e distintas concepções e demandas.

\section{INTRODUÇÃO}

As palavras "movimento" e "participação" passaram a ser incorporadas ao tema da saúde. Esses dois conceitos remontam a diferentes tradições da ação social, que vem sendo superpostos nas referências feitas ao sentido e à organização pública desse setor.

O termo "movimento" ou "movimentos sociais" passou a ser usado de forma abrangente, como referência para designar todo tipo de manifestação coletiva. 
Nesse sentido passou a ser muitas vezes contraposto à "participação", que durante os anos 60, incorporou a conotação de cooptação institucional.

A discussão estruturalista nos anos 60 e 70 difundiu a rejeição das "práticas institucionais" fosse pela crítica ao "sistema capitalista", fosse pela crftica cultural às "práticas sociais" como práticas de controle. O termo "movimento social" ganhou o caráter de protesto, rejeição às formas dominantes da sociedade, aderindo, conseqüentemente, à crttica cultural do conhecimento, das formas de sociabilidade e de poder.

A idéia de "participação", por outro lado, dentro da "teoria da democracia" nos países ocidentais e no pós guerra vinculava-se a uma teoria instrumental da democracia , como "sistema polftico institucional" que necessitava se aperfeiçoar para conquistar bases de legitimidade politica. Como corolário, pode-se colocar que a participação desenvolve-se com a integração da maior parcela da população às instituições do Estado e da sociedade. Exemplo mais evidente desse fato seria a integração ao sistema escolar: quanto mais indivíduos matriculados em escolas, maiores as exigências de consumo material e cultural, gerando o aumento da "mobilização de recursos", aumentando o índice de participação na sociedade.

Além desses meios de integração, o sistema poltico deve abrir canais visando a participação dos indivíduos em suas instituições. Para os defensores desta democracia da integração restariam os "grupos residuais" que, situando-se marginalmente aos recursos materiais ou educacionais da sociedade, oporiam-se à participação.

A participação democrática teria o seu desenvolvimento a partir de canais institucionais estabelecidos para a detecção de demandas de distintos grupos da sociedade; essa seria tanto mais desenvolvida quanto maior sua capacidade de 
previsão das áreas de possíveis atritos. Nessa perspectiva os "movimentos sociais" e as formas de ação coletiva restringir-se-iam a instrumentos de pressão para se obter maiores recursos - econômicos ou políticos - para os grupos neles envolvidos (5).

A construção de uma teoria contemporânea sobre os "movimentos sociais" vincula-se a tradições que interpretam a sociedade como construção histórica e campo de conflitos, tomando como base e modelo histórico desse conflito o movimento operário, que veio trazer mudanças às sociedades ocidentais durante o século XIX.

Esse modelo de pensamento da sociedade como campo de conflitos históricos incorpora novos significados, como a própria idéia de democracia enquanto produto da expressão do sentido das ações sociais na esfera pública. Nesta, entrariam em conflito as concepções sobre o modo de organização e de vida em sociedade a partir do significado e da ação dos atores sociais em confito. Enquanto tal, a idéia de movimento social sugere temas como o da ação coletiva, das identidades culturais, do direito em função da mudança social e da perspectiva da sociedade como campo em construção.

No Brasil, o tratamento dos temas "Movimento Social" e ""Participação", em período recente, incorpora em suas análises essas diferentes tradições e assim penetra na discussão das "áreas sociais", como é o caso da prestação de serviços de saúde e seu sentido público.

$\mathrm{Na}$ década de 70, termos como "instituição", "práticas sociais", "movimentos sociais", a partir de uma leitura estrutural da sociedade, expressam tanto a idéia de oposição institucional como de extensão dos direitos. Na década de 80, "movimento social" e "participação" são interpretados seja como inovadores da cena política, seja como instrumentos de aperfeiçoamento das instituições da 
sociedade. No sentido de oposição, esses aparecem tanto na qualidade de movimentos populares que buscavam pressionar o Estado a realizar suas tarefas no campo social (8), quanto na qualidade de palco de expressão de novas identidades sociais e polfticas que se oporiam à polftica e às interpretações tradicionais da sociedade (6). No sentido da extensão de direitos e enquanto participantes da política social do Estado, os "movimentos sociais" são interpretados como constituição de interlocutores que passam a ser reconhecidos pela burocracia estatal (4); levariam igualmente à formação de novas identidades que incorporariam aspectos da sociabilidade local à esfera pública (2). Neste entendimento da questão, "movimento/participação" expressariam, ao mesmo tempo, oposição ao Estado, instituição de novas identidades e participação na burocracia pública como busca de incorporação de direitos.

\section{A PROBLEMÁTICA EM SÃo JOSÉ dOS CAMPOS}

Buscando identificar tipos de ação e atores sociais que se expressam em torno da saúde, realizou-se uma pesquisa de campo, entre 1989 e 1991, no Município de São José dos Campos, São Paulo (1). Nesse município é notória a presença de um Movimento Sindical, vinculado às grandes indústrias privadas e estatais que, desde sua implantação, desenvolveram um sistema de atendimento à saúde através de convênios com grupos locais de prestação de serviços de saúde.

Ao lado do Movimento Sindical, que passa a inscrever a questão dos convênios juntamente com as reivindicações salariais, observou-se a existência de atores sociais do setor público que expressavam um discurso de oposição política e sindical, dirigindo-se à Prefeitura e à elite dominante local. Nesse discurso inscreviase a denuncia da privatização e da manipulação das instituições públicas, a crtica à desigualdade, a reivindicação da generalização de direitos e o apelo a uma discussão 
pública a respeito das polfticas de uso do espaço e dos investimentos estatais no município.

$\mathrm{Na}$ história recente do município encontra-se o registro do tema da "participação", vinculado ao sistema politico e empresarial local desde a década de 70. Do ponto de vista do "sistema" de integração e legitimação politica pode-se dizer que o tema aparece durante os anos 70 . Nesse sentido, altas taxas migratórias aliadas a investimento industrial- tanto por parte de estatais como por parte de capital externo- bem como dotação de infra-estrutura a partir do poder municipal e das empresas funcionariam como "sistema de integração".

Nesse período, a expansão do emprego possibilitou o desenvolvimento da cidade, com a oferta de lotes por parte das imobiliárias e a expansão da infraestrutura urbana implementada pelo Poder Municipal, juntamente com a integração aos convênios intermediados pelas empresas.

No caso do Poder Municipal, mesmo durante a fase em que os Prefeitos eram nomeados pelo Governo Federal, esses, juntamente com a Câmara Municipal, estabeleciam um circuito de legitimação polftica através das sociedades de bairro e das melhorias desses. Os serviços de saúde administrados pela esfera estatal, nessa conjuntura não ocupam cena de destaque, existindo para a população de menor renda que, com emprego fixo ou não, deixando de possuir convênios, identificava-se como carente.

No plano da ação política, o circuito de organizações de bairro e prefeitura mantém-se e é reforçado mesmo após o período da "transição democrática" e da crise política do regime militar no Brasil. As eleições diretas para prefeito incorporam as mobilizações democráticas a esse circuito trazendo porém para a cena política a expressão dos atores de oposição política. No plano local e 
especificamente na área dos serviços de saúde, a "transição democrática" traz à cena a reivindicação dos serviços nos bairros, com a incorporação de agentes populares e o tema da saúde e saneamento.

O movimento sindical, ganharia expressão a partir da década de 1980, quando elementos da oposição sindical passam a ser eleitos para diretorias Sindicais, destacando-se na cena sindicatos como o dos metalúrgicos e dos petroleiros.

O início dos anos 90 traz a agudização de um processo de crise de crescimento do município, a partir da polftica recessiva e do desenvestimento estatal, aumentando o contingente de desempregados e diminuindo a perspectiva de integração e os mecanismos de ascensão econômica, constituindo um novo cenário para os atores sociais e a administração dos serviços estatais.

Nesse quadro, os atores sociais que se relacionavam ao campo da saúde como projeto e como prestação de serviços encontravam-se polarizados por dois planos de ação: a ação política e o movimento sindical.

Nos atores sociais encontrados durante a pesquisa de campo, identificou-se a confluência desses planos de ação, que denominou-se de "participação" e "movimento", seja pela relação com a ação politica e local, seja pelo conflito em relação ao modo de organização da vida local.

A partir da pesquisa empreendida, tornar-se-iam mais claros as distintas ações presentes no cenário dos "movimentos" e da "participação" na esfera local e suas relações históricas.

No plano descritivo esses atores encontram-se- na rede de prestação de serviços de saúde, em organizações locais, de bairro e nos organismos institucionais de participação bem como na esfera sindical. 
A pesquisa empreendida iniciou-se a partir de um evento: a greve ocorrida na rede municipalizada de saúde em 1990. Esse "movimento", assim denominado por seus atores, expressou-se inclusive com manifestações de rua, definindo seu sentido "público" a partir desse espaço, que em termos da história nacional recente, definiu-se como território de oposição.

Nos discursos expressos pelos atores "da saúde", que foram registrados tanto a partir da observação dos eventos, como em entrevistas posteriores, destacam-se distintas temáticas.

Os atores "internos" aos serviços de saúde, manifestando-se na esfera pública, realizavam a vinculação de uma reivindicação sindical, a de aumento dos salários dos trabalhadores da saúde, assim expressos como atores sindicais, e uma reivindicação organizativa: o aumento de leitos "públicos" para internação no sistema municipal de saúde. $O$ termo "público" era assim empregado em oposição à particular, privado. Essa referência "público/privado", associada ao caráter sindical, traduz-se em duas ambivalências: a reivindicação sindical, privativa de uma categoria, os funcionários ou "trabalhadores" públicos "da saúde" reivindicando a extensão de seu campo, o qual, por sua vez, opõe, no cenário público, a ambiguidade do acesso aos serviços.

Junto ao discurso sindical compõe-se portanto uma reivindicação organizativa, que se dirigia ao plano político, o poder municipal, e uma orientação a respeito da sociedade, envolvendo uma função pública, de atendimento universal a seus cidadãos.

Essa referência pública: a idéia de cidadania, que transparece aliada à reivindicação corporativa, embasa-se em outros temas "internos" e "externos" aos serviços de saúde e ganha distintos perfis a partir da diversidade dos "atores da 
saúde"

Entre os médicos, os temas recorrentes dizem respeito a aspectos como: a crise de opções no mercado local de trabalho, as diferenças existentes entre a própria categoria e a referência a "ser cidadão", e, nessa categoria, opor-se às formas de organização dos serviços de saúde, com sua orientação para a sociedade. A critica à própria categoria e sua divisão interna faz referência, por sua vez, aos outros "trabalhadores de saúde", definidos como "pessoal de enfermagem".

Nessa classe encontram-se os "agentes de saúde", que traduziam suas demandas através de um discurso em relação à organização dos serviços e uma orientação em relação à sociedade. No primeiro plano, expressavam a reivindicação de uma maior autonomia por referência ao trabalho em saúde: de "agentes de saúde" que eram, haviam se tornado "atendentes", que haviam perdido o domínio de seu trabalho, que deveria ser o de "saúde pública", através de visitas domiciliares, campanhas de prevenção, etc.. No atual modelo de organização sentiam-se subordinados ao atendimento médico e, ao mesmo tempo, pressionados pela população, clientela dos serviços.

Em relação a essa população manifestavam uma proximidade e um sentimento de indignação.

Os "agentes de saúde", desqualificados enquanto técnicos, traduziam sua indignação através da experiência de sua forma de sociabilidade com a população, traduzindo a idéia de direito no sentimento de expropriação e injustiça. A população, antes de pertencer a um mundo dos cidadãos, aparece como a população que sofre a " dor". Os serviços não se importam com essa condição peculiar a um tipo de experiência de vida e de sociabilidade, possível de ser compartilhada entre iguais, numa relação mais próxima da atenção, da identificação. 
A idéia de direito é colocada como uma questão de justiça, de retribuição a um mundo de dificuldades e falta de reconhecimento. É a partir do reconhecimento e da legitimação que essa categoria de trabalhadores de saúde reivindica sua legitimidade, chamando atenção para um universo que estaria alheio ou encoberto no circuito dos "profissionais" e do "nivel central".

A recorrência a ação coletiva a partir de contextos como a sociabilidade aparece também entre os atores "externos" aos serviços de saúde, que se organizam a partir do plano local, de sua inserção no contexto da cidade.

Como formas de sociabilidade que se dirigem à reivindicação ou à construção de direitos ou de mecanismos de intervenção sobre as decisões sociais destacam-se tanto a solidariedade, na tradição do exercício de um direito, tal como descrito por DURHAN (2), como a idéia de controle e hierarquia.

No primeiro caso, entre atores que participavam do núcleo de saúde de uma unidade local de serviços, aparecem como temas a luta contra uma empresa poluidora, que busca aglutinar a população local frente a um problema compartilhado e a experiência pessoal, a partir de um caso de infecção hospitalar, que coloca a extensão da vivência individual na esfera da reivindicação de um direito: a do controle da qualidade dos serviços. Esses temas aparecem no contexto da ação local da Igreja e de atores de oposição política.

Em outro contexto de ação local encontra-se o tema da participação no jogo político, buscando-se resultados diretos para o contingente da população menos "integrada" à economia da cidade. Nesse discurso as referências diziam respeito a astúcia e habilidade em obter reivindicações a partir de um relacionamento com o poder executivo local, e, em contrapartida, exercer um controle e disciplina dos grupos liderados. Nesse contexto, a idéia de saúde é expressa como a da 
conquista das condições mínimas de existência como casa para morar e alimento para comer, traduzindo portanto estas reivindicações um plano instrumental e imediato.

No contexto da participação institucional encontram-se os atores que, ocupando a representação no Conselho local de Saúde, manifestam sua ação através da fiscalização e da denúncia. Ou procurando tornar público o exercício político, que se dá no plano das negociações e dos interesses privados.

Esse grupo de atores vinculava-se tanto a um plano de ação polftica de oposição como à defesa de uma orientação cultural para a sociedade: a de exercer, pela representação em órgãos institucionais, o papel de fiscalização e de formação de uma ética pública.

No plano dos sindicatos, a questão da saúde encontra-se cindida entre a ação reivindicativa sindical - a perspectiva de organização de bases de atuação no interior das empresas- e a ação no cenário político mais geral, de oposição e reivindicação de serviços do Estado.

No primeiro caso, no plano da reivindicação sindical, os serviços de saúde colocam-se como benefícios a serem conquistados. Os convênios de saúde tornar-se-iam objeto de negociações com as empresas, na ótica do aumento das possibilidades desse consumo, oferecido, em diferentes modalidades, pelas empresas estatais e privadas. A partir da recessão e dos cortes ocorridos nos convênios saúde, os atores sindicais passam a problematizar a questão da qualidade desses serviços. Além do convênio saúde, a discussão se dá em torno do seguro de vida nele embutido, vislumbrado como uma forma de poupança ou de indenização compensatória para a familia dos trabalhadores.

Em termos da formação de bases sindicais, a ação em torno da luta pela 
saúde nos locais de trabalho traduz um conflito de orientações entre a descrita lógica da empresa e dos patrões e a lógica dos trabalhadores. Expressando o conflito clássico do movimento operário entre patrões e empregados, concentra a discussão sanitária no interior do processo de produção, subordinando as questões do cotidiano dos trabalhadores fora da fábrica.

Esses aspectos da ação sindical- militância interna às fábricas e reivindicações para aumento do consumo ou das indenizações compensatórias de cada empresa- tendem a esvaziar ou tornar menos evidente a sua ação em relação à saúde no cenário político local e nacional.

Desse modo, a esfera de ação sindical toma um caráter transverso ao penetrar a esfera de ação dos trabalhadores do setor saúde sem entretanto dirigir-se propriamente à questão da prestação de serviços de saúde no âmbito da esfera pública. $O$ cenário de recessão e desemprego contribui para que o problema da prestação de serviços de saúde, bem como a situação da previdência venham a se deslocar para um espaço de maior destaque. Essa questão, entretanto, passa a ser incorporada a uma estratégia de oposição política dos sindicatos, que situam o campo adversário muito mais no plano nacional do que local, deixando de dirigir-se mais especificamente à organização e a orientação local dos serviços de prestação de saúde.

A essa dimensão descritiva das ações, temas e problemas pertinentes aos atores sociais e à saúde, cabe indagar sobre a questão da existência de um "movimento social" em relação à saúde, ou por extensão às áreas sociais. 


\section{CONCLUSÕES}

A discussão a respeito dos movimentos sociais na sociedades contemporâneas toca em dois aspectos que têm sido apresentados por autores como HABERMAS (3) (em relação à realidade da social- democracia européia e ao contexto politico norte americano) e TOURAINE (7), que investiu no sentido da construção de uma teoria a respeito dos movimentos sociais.

No plano da discussão sobre os países europeus de regime socialdemocrata coloca-se o problema do esgotamento das "energias utópicas", ou seja da crise da ideologia do trabalho liberado ou do projeto socialista. Essa crise utópica focaria os horizontes das reivindicações no aumento da extensão e qualidade das "indenizações compensatórias"(a partir dos senviços estatais de seguridade e saúde) e na diminuição do tempo de trabalho. Essa orientação para as demandas sindicais e polfticas deslocaria os papéis dos cidadãos participantes do contexto polftico para clientes da burocracia dos serviços do Estado e esbarraria nas orientações das elites econômicas de cada um dos países, dispostas a empreender politicas de atração de capitais, ou de aumento da produtividade dos setores terciários, que se confrontariam com a extensão dos benefícios sociais.

No tocante à teorização de um movimento social, por outro lado, esse tem sido conceituado a partir de seu sentido histórico e da disposição de seus atores a entrarem em conflito a partir de orientações culturais a respeito da sociedade. Esses temas, no contexto dos países europeus, têm sido focalizados através de aspectos como o desemprego, a imigração, os adolescentes de regiões desindustrializadas ou marginalizados da esfera de consumo etc...

No contexto brasileiro, a partir das observações e reflexões realizadas, pode-se referir a questão da existência de um movimento social, a partir do que ficou 
chamado de "transição democrática". Este Movimento social, por sua vez colocar-seia, em termos históricos, na derivação das oposições políticas a partir das organizações de esquerda e de suas manifestações mais recentes, no contexto dos anos 60 e 70 . Tais manifestações se expressariam, a partir de meados dessa última década, em planos variados $e$, de maneira mais aguda, em determinadas conjunturas, traduzidas por distintos atores: do bairro, do sindicato, do partido polftico ou dos canais de participação institucionais.

A ação coletiva nas áreas sociais e, dentro delas, no campo da saúde, não corresponderiam a "movimentos sociais" com caráter autônomo, capazes de gerar condutas de conflito por diferentes orientações culturais no campo da saúde. As demandas nesse campo colocar-se-iam no plano organizativo e no seu limite no plano do confronto político em termos de sua organização. A saúde, bem como outras áreas sociais, passariam a expressar esse movimento mais geral, que encontra-se em processo, e que teria em seu horizonte a perspectiva de orientação cultural por uma sociedade que incorporasse seus contingentes marginalizados, diminuísse as disparidades sociais existentes e estabelecesse outros critérios de relação no plano jurídico-politico.

\section{BIBLIOGRAFIA}

1. ADORNO,R.C.F. A trajetória do movimento e da participação: a conduta dos atores sociais na saúde. São Paulo, 1992. [Tese de Doutorado Faculdade de Saúde Pública da USP].

2. DURHAN,E.R. Movimentos sociais, a construção da cidadania Novos Estudos CEBRAP, 10:24-31, 1984.

3. HABERMAS, J. A nova intransparência . Novos Estudos CEBRAP, 18:103-14, 1987.

4. JACOBI, P. Movimentos sociais e políticas públicas. São Paulo, Cortez Editores, 1989. 
5. LAPEYRONNIE, D. Mouvements sociaux et action politique existe- $t$ - il une théorie de la mobilisation de ressources. Rev.franc.Sociol., 29:593-616,1988.

6. SADER, E. Quando novos personagens entraram em cena: experiências, falas e lutas dos trabalhadores da Grande São Paulo,1970-80. Rio de Janeiro, Paz e Terra, 1988.

7. TOURAINE, A. Le retour de l'acteur. Paris, Fayard, 1984.

8. VALLA,V.V. \& SIQUEIRA,S.A.V. O centro municipal de saúde e a participação popular. In: Costa,N.R., org. et al. Demandas populares, políticas públicas e saúde. Petropolis, Vozes, 1989. p.:45-65. 